\title{
PSEUDOMONAS BRAIN ABSCESS WITH CALCIFICATION IN 40 DAY INFANT: AN UNUSUAL CASE
}

Shiju Kumar C1, Jayaram Das², Shajehan S3, Prameela Joji ${ }^{4}$

\section{HOW TO CITE THIS ARTICLE:}

Shiju Kumar C, Jayaram Das, Shajehan S, Prameela Joji. "Pseudomonas brain abscess with calcification in 40 day infant: an unusual case". Journal of Evolution of Medical and Dental Sciences 2013; Vol2, Issue 36, September 9; Page: 6861-6863.

ABSTRACT: Reporting 40 day old child referred from a private clinic to our hospital with CT Brain showing intracranial space occupying lesion. Child had fever since day 7 of birth and was evaluated for sepsis in the nearby hospital and CSF study showed features of bacterial Meningitis and was treated for 14 days with inj. cefotaxime and amikacin. After 3 days of IV medication fever subsided. CSF culture outside did not shown any growth. We have not got the detail of blood investigation outside. CT brain was taken in that private clinic to rule out post meningitic complication. Surprisingly they found intracranial space occupying lesion. So the child was referred to our hospital for further management.

On examination child was alert, active feeding well, no any neurological deficit anterior fontanelle was level. Blood investigation showed normal total count 13,000 with polymorphs predominance 70\%), CRP was 7 and blood culture has not grown any bacteria. Serum calcium $8 \mathrm{mg} / \mathrm{dl}$, potassium 4meq, sodium $130 \mathrm{mEq}$.

CT Brain (taken outside) showed well encapsulated calcified mass in right temporal lobe $3 \times 3$ $\mathrm{cm}$ with no midline shift. So child was operated (open surgery) and biopsy of the lesion showed abscess with calcification. Pus culture revealed pseudomonas aeruginosa. Child was treated with IV ceftazidime for 10 days. Child went home with no neurological deficit. On follow up he is doing well.

DISCUSSION: Calcified brain abscess ${ }^{1}$ in infancy is rare and only few cases were reported with abscess and calcification. Brain abscesses can occur in children of any age but are most common in children between 4 and $8 \mathrm{yr}$ and neonates. The cause of brain abscess include embolization due to congenital heart disease with right to left shunts, meningitis, chronic otitis media, sinusitis, orbital cellulitis, dental infection, immunodeficiency and infection of ventriculoperitoneal shunts.

Our patient had CSF proven meningitis treated with antibiotic for 14 days. He did not have any neurological symptoms inspite of this large lesion. Intrauterine viral infection followed by calcification has been very well documented, but bacterial infection followed by calcification is very rarely reported.

In literature only few cases of brain abscess with calcification is reported and pseudomonas brain abscess in infants has not been reported till now as per available literature, so we are reporting this rare case, from our institution.

Auvichayapat et $\mathrm{al}^{2}$ reviewed the clinical features and outcomes of treatments of 107 infants and children with brain abscesses. Congenital heart diseases and chronic otitis media were the most common predisposing factors. The common signs and symptoms were fever, headache, vomiting, alteration of consciousness, and focal neurologic deficit. The overall mortality rate was $10.7 \%$.

Calcified brain abcess in a 6 year old child reported by Kabre et $\mathrm{al}^{3}$. Pus culture showed staph aureus. 
A case of Klebsiella brain abscess was reported by Qureshi et al ${ }^{4}$ in a neonate. Diagnosis of abscess was confirmed by magnetic resonance imaging and ultrasound-guided aspiration.

\section{CT BRAIN (PLAIN)}

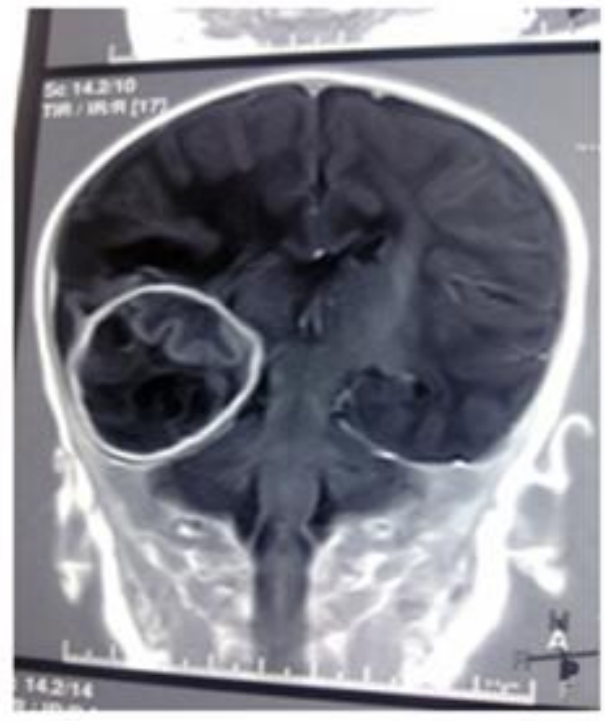

Figure 1 : coronal view of plain CT brain showing well defined mass $3 \times 3 \mathrm{~cm}$ in the right temporal lobe encapsulated by calcification.

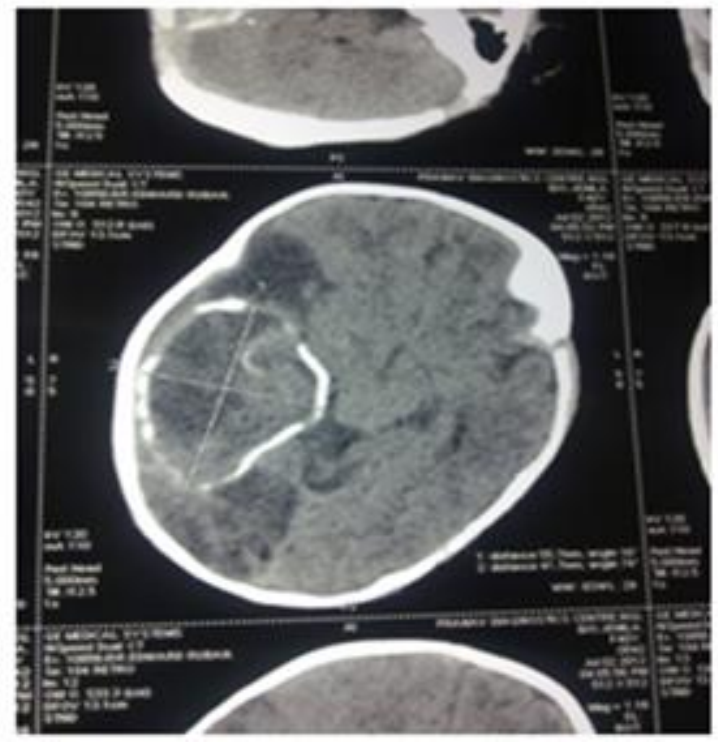

Figure 2: axial view of plain CT brain plain mass in the right temporal region encapsulated by calcification with perilesional edema (no midline shift)

\section{REFERENCES:}

1. Behrman RE, Kliegman RM, Jenson HB, Staton BF. Nelson Textbook of Pediatrics $19^{\text {th }}$ Edition. Philadelphia Elsevier: 2098 - 99.

2. Auvichayapat $\mathrm{N}$, Brain abscess in infants and children: a retrospective study of 107 patients in northeast Thailand, J Med Assoc Thai. 2007 Aug; 90(8):1601-7.

3. Kabré A, Ba MC, Kabore BJ. Calcified brain abscess; Dakar Med. 2002;47(2):194-6.

4. Qureshi UA, Klebsiella brain abscess in a neonate. Arch Dis Child Fetal Neonatal Ed. 2011 Jan; 96(1): F19. 


\section{AUTHORS:}

1. Shiju Kumar C.

2. Jayaram Das

3. Shajehan S.

4. Prameela Joji

\section{PARTICULARS OF CONTRIBUTORS:}

1. Resident, Department of Paediatrics, KIMS Hospital, Trivandrum, Kerala.

2. Pediatrician, Department of Paediatrics, KIMS Hospital, Trivandrum, Kerala.

3. Neurosurgeon, Department of Paediatrics, KIMS Hospital, Trivandrum, Kerala.

4. Paediatrics, Department of Paediatrics, KIMS Hospital, Trivandrum, Kerala.

\section{NAME, ADDRESS, EMAIL ID OF THE}

\section{CORRESPONDING AUTHOR:}

Dr. Shiju Kumar C.,

Resident,Department of Pediatrics,

Kims Hospital, Anayara Post,

Pin - 695029.

Email - dr.shijukumar@gmail.com

Date of Submission: 20/08/2013.

Date of Peer Review: 22/08/2013.

Date of Acceptance: 29/08/2013.

Date of Publishing: 03/09/2013 